\title{
IMPLEMENTASI APLIKASI MENU PADA RESTORAN JAPANESE FOOD KENZO BENTO BANJARMASIN
}

\author{
Muhammad Amin, M.Kom \\ Fakultas Teknologi Informasi, UNISKA \\ Email : maminbjm58@gmail.com
}

\begin{abstract}
ABSTRAK
Sebagai salah satu restoran baru berkonsep Japanese food khususnya menu bento dan mie ramen, restoran kenzo bento banjarmasin sudah menggunakan sistem komputerisasi, tetapi hanya sebatas di bagian pembayaran saja. Untuk membatu pelayanan agar lebih cepat dan bisa langsung terhubung dengan koki didapur maka kami merancang suatu sistem aplikasi menu restoran untuk rumah makan/ restoran kenzo bento Banjarmasin Menggunakan Bahasa pemrograman PHP dan database MySQL. Kendala yang sering dihadapi oleh sebuah restoran yang masih menggunakan pelayanan dan sistem manual yaitu pekerjaan lebih lama dan tidak efisien. misalnya saja saja pemesanan menu ke koki didapur. Dengan adanya aplikasi ini maka pemesanan menu kekoki bisa lebih cepat.
\end{abstract}

KeyWord : Menu ,MySQL , PHP, Restoran

\section{PENDAHULUAN}

Software Restoran atau Program Restoran adalah aplikasi komputer yang dikembangkan khusus untuk bidang jasa restoran, rumah makan dan cafe, Aplikasi ini sudah mendukung bisnis proses operasional sehari-hari serta saling terintegrasi . Aplikasi ini di develop berbasis desktop dan berjalan di sistem operasi windows, sehingga dapat memudahkan user dalam penggunaannya, Aplikasi ini juga sudah di design untuk ruang lingkup Local Area Network (LAN).

Dalam aplikasi ini antara modul dan sub modul sudah terintegrasi, sehingga setiap pelaporan dan data transaksi dapat dilihat secara real time, tanpa harus menunggu proses akhir hari (EOD), detail dari modul, sub modul dan report aplikasi terlampir

Aplikasi ini mengadministrasi kegiatan operasional dari front sampai back-end antara lain: memanage data customer, data supplier, master menu dan recipe, transaksi penjualan, join table, transfer table, transfer menu, pembelian, retur pembelian, inventory, data hutang, data piutang, data stok, transaksi jurnal, kas/bank, fix asset, laporan rugi/laba, neraca dan laporan-laporan lainnya
Diharapkan dengan adanya aplikasi ini dapat membantu management dan karyawan dalam menjalankan operasional dan juga berfungsi untuk monitoring dan dapat meningkatkan layanan restoran

\section{RUMUSAN MASALAH}

Berdasarkan latar belakang tersebut dapat dirumuskan masalahnya adalah mengembangkan kembali sistem sebelumnya yang kompleks menjadi sistem yang lebih simple, efisien, dan informatif bagi pengguna.

\section{TUJUAN DAN TARGET LUARAN}

1. Membuat Aplikasi yang mudah digunakan.

2. Membuat sistem online agar mudah diakses dimana saja

3. Target luaran wajib dan tambahan dalam pembuatan penelitian ini yaitu akan dipublikasikan dalam jurnal lokal yang mempunyai ISSN atau jurnal nasional terakreditasi dan sesuai bidang ilmu seperti Jurnal Techonogia 


\section{METODE PENELITIAN}

Pada penelitian ini penulis menggunakan beberapa metode pengumpulan data sebagai berikut :

a. Metode Observasi

Observasi atau pengamatan merupakan salah satu teknik pengumpulan data atau fakta yang cukup efektif untuk mempelajari suatu sistem. Observasi adalah pengamatan langsung para pembuat keputusan berikut lingkungan fisiknya atau pengamatan langsung suatu kegiatan yang sedang berjalan. Pada tahap ini penulis melakukan pengamatan terhadap kegiatan, proses, dan alur masuk dan bagaimana keluar barang di gudang pada perusahaan tersebut

b. Metode Wawancara

Wawancara merupakan salah satu teknik pengumpulan data yang penting dan banyak dilakukan dalam pengembangan sistem informasi. Wawancara memungkinkan analis sistem sebagai pewawancara untuk mengumpulkan data secara tatap muka langsung dengan orang yang diwawancarai. Adapun orang-orang yang diwawancarai adalah Pimpinan dan Petugas dan staff admin pada perusahaan tersebut

Analisis sistem adalah suatu proses mengumpulkan dan menginterpretasikan kenyataan-kenyataaan yang ada, mendiagnosa persoalan dan menggunakan keduanya untuk memperbaiki sistem. Pada tahap ini penulis lakukan adalah :

a. Mengidentifikasi masalah untuk mendapat pengertian sebenarnya dari masalahyang dihadapi yaitu dengan mengidentifikasikan penyebab masalah dan bagaimana langkah untuk menyelesaikannya.

b. Memahami sistem kerja yang ada dengan mengumpulkan data hasil penelitian dan memahami sistem yang ada.

c. Menganalisa kelemahan sistem dan kebutuhan informasi

\section{ANALISA HASIL DAN PEMBAHASAN}

\section{Hasil Pengumpulan Data}

a. Pengumpulan Kebutuhan

Tahap ini menganalisa masalah dan kebutuhan yang harus diselesaikan dengan sistem komputer yang akan dibuat. Tahap ini berakhir dengan pembuatan laporan kelayakan yang mengidentifikasi kebutuhan sistem yang baru dan merekomendasikan apakah kebutuhan atau masalah tersebut dapat diselesaikan dengsn sistem komputer yang ada.

b. Analisa Kebutuhan

Tahap ini melakukan rancangan design sistem. Tahap ini memberikan rincian kinerja program dan interaksi antara user dengan program tersebut.

c. Pemrograman

Tahap ini adalah spesifikasi design yang telah dibuat untuk diterjemahkan de dalam program / instruksi yang ditulis dalam bahasa pemrograman.

d. Pengujian

Tahap ini semua program digabungkan dan diuji sebagai satu sistem yang lengkap untuk menjamin sumua berkerja dan memenuhi kebutuhan penanganan masalah yang dihadapi.

e. Pemeliharaan

Tahap ini merupakan pengaplikasian program yang telah dibuat untuk digunakan secara utuh dan masalah baru yang muncul sebagai bahan masukan untuk memperbaiki sistem program yang baru.

\section{Desain Sistem \\ Desain Sistem}

1. Diagram Kontex 


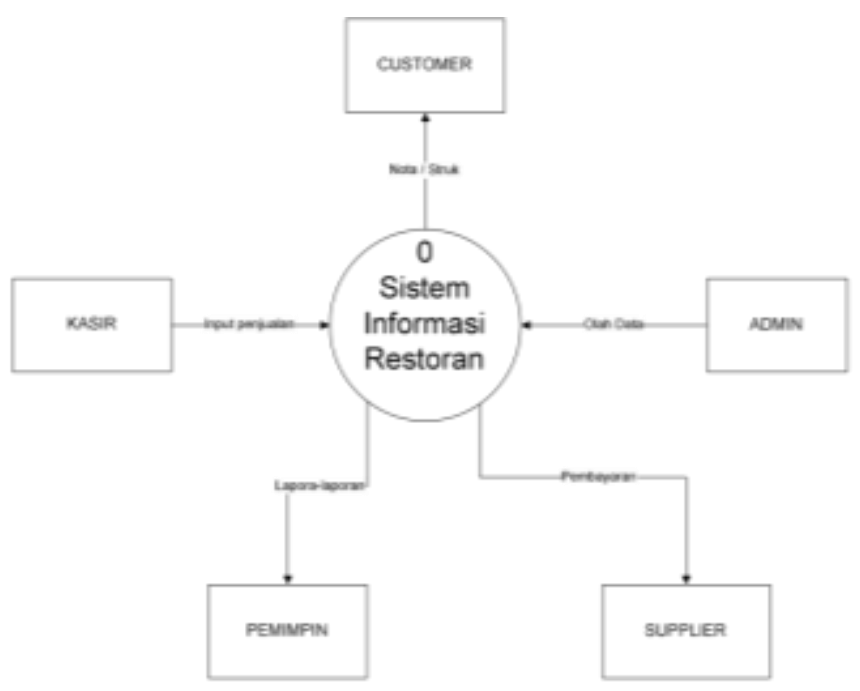

Gambar 5.1 Diagram Kontex menu

2. DFD Level 1

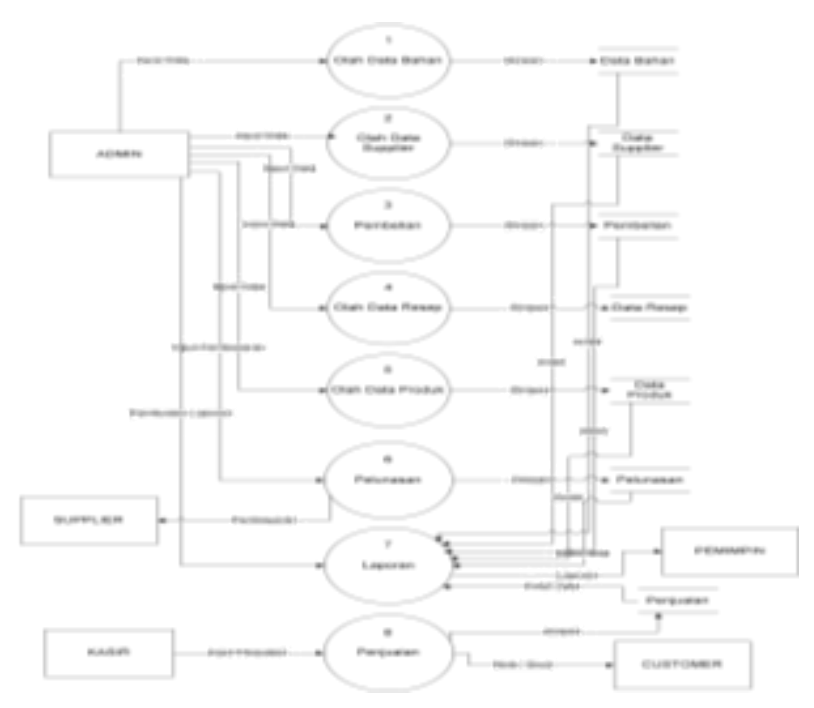

Gambar 5.2 DFD level 1

6. IMPLEMENTASI PROGRAM

Tampilan antar Muka Sistem

Menu utama adalah tampilan Menu menu yang ada di restoran kenzo. 


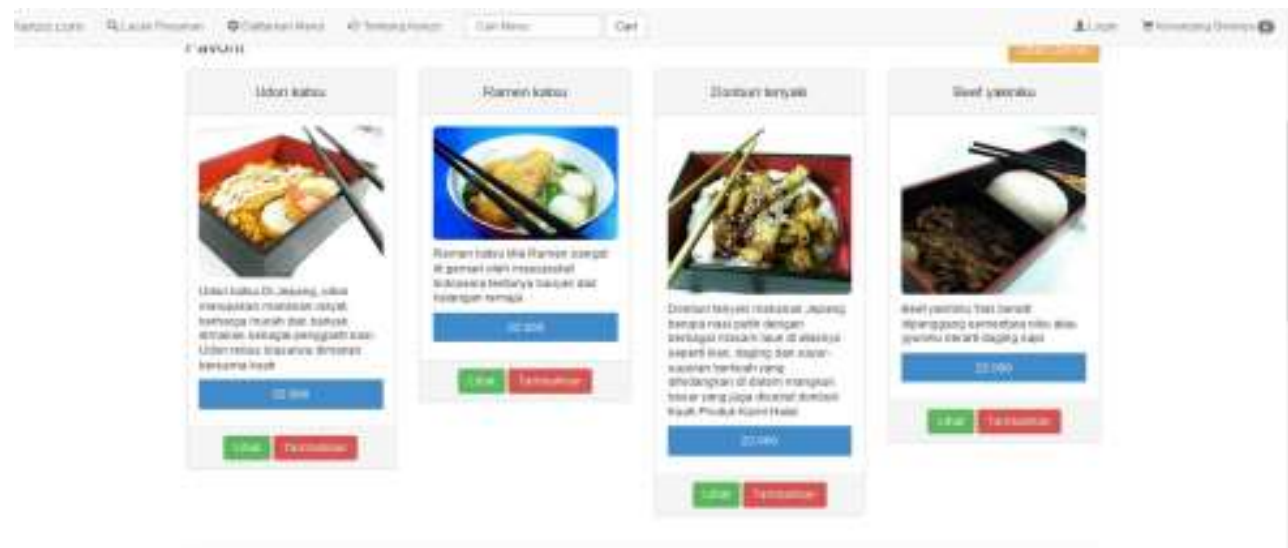

Gambar 6.1 Daftar menu Kenzo

Pada daftar menu makanan terdapat menzoom gambar makanan serta menu tambahkan untuk pemesanan makanan tersebut. foto gambar makanan, harga, menu lihat untuk

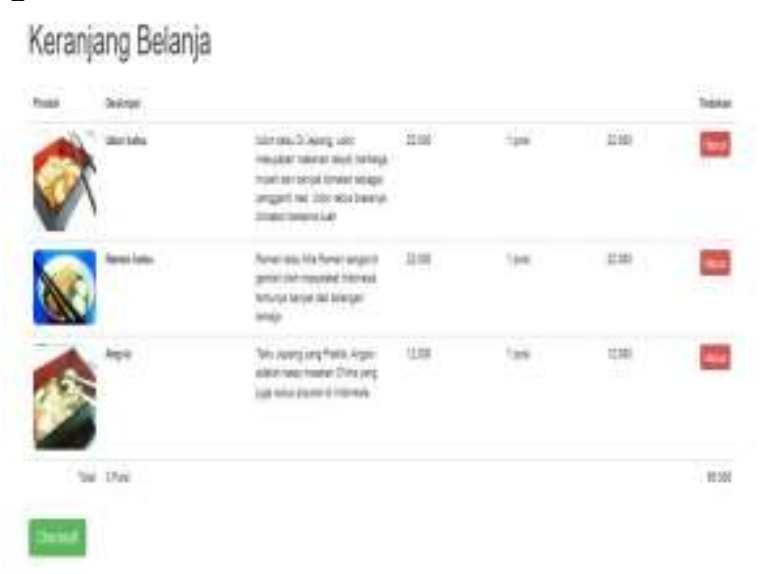

Gambar 6.2 Keranjang Belanja pesanan

Pada Keranjang Belanja pesanan terdapat deskripsi menu yang sudah dipesan lengkap dengan total harga makanan yang harus

$$
\text { Checkout }
$$

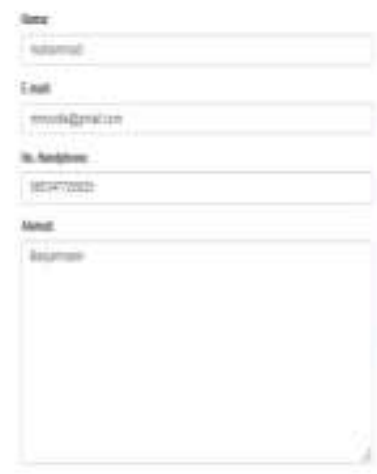

Gambar 6.3 Menu Check out dibayar. Pada menu ini terdapat tindakan hapus untuk mengcancel makanan yang tidak jadi dipesan.

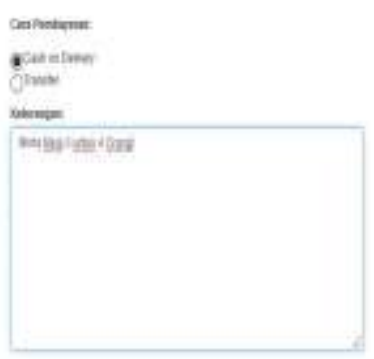


Pada Menu Check Out terdapat data yang harus

, alamat serta cara pembayaran secara COD diisi pemesan yaitu nama, email, no.handphone maupun transfer jika pesanan secara online.

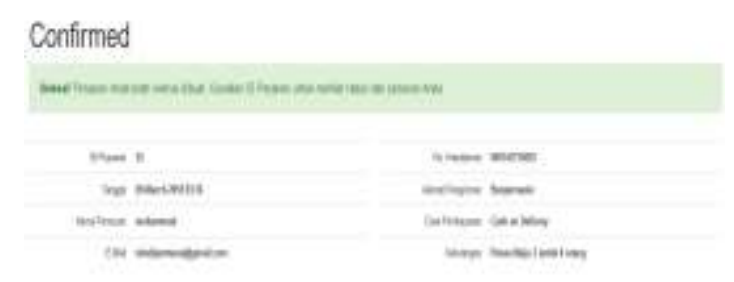

Gambar 6.4 menu confirmed

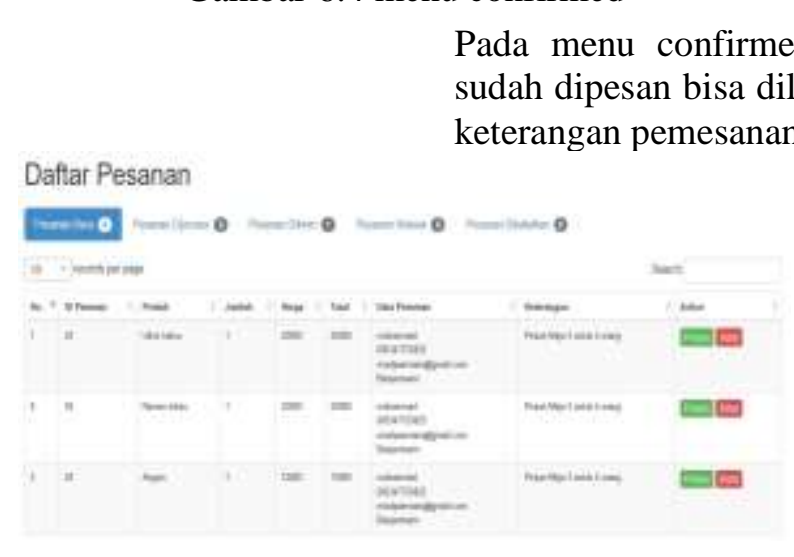

Gambar 6.5 Daftar pesanan1

Pada Daftar Pesanan akan diterima Oleh Pihak dapur yaitu Koki untuk memproses pesanan/ pesanan baru, pesanan yang diproses, pesanan Action. Pada daftar pesanan terdapat menu dikirim, pesanan selesai dan pesanan yang dibatalkan.

\section{Daftar Pesanan}

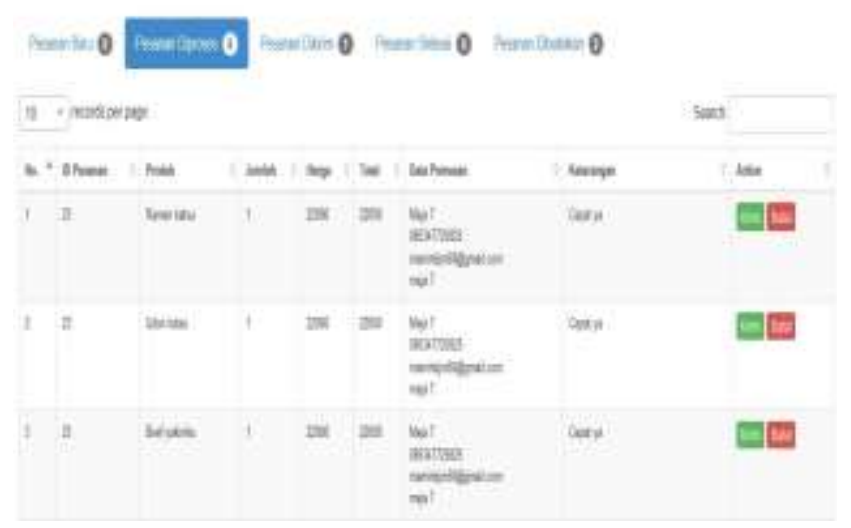

\section{Gambar 6.6 Daftar pesanan2}




\section{PENUTUP}

\section{KESIMPULAN}

Kesimpulan dari penelitian yang telah dilakukan adalah sebagai berikut :

1. Dengan adanya Aplikasi menu seperti ini, akan membantu pemesanan menu elanggan atau costumer restoran Japanese Food Kenzo Bento Banjarmasin. Selain itu , 2. pemesanan yang langsung menghubungkan ke dapur akan mempercepat proses pemesanan karena koki akan langsung tau pemesanan pelanggan

\section{SARAN}

Saran dari penelitian yang telah dilakukan adalah sebagai berikut :

1. Untuk penelitian selanjutnya dapat menggunakan Bahasa pemrograman lain, untuk mengkomparasi hasil program ini.

2. Untuk Kedpan perlu adanya kerja sama pembayaran Online dengan pihak ketiga yang terintegrasi.
[1] Agus Hariayanto . (2016).Membuat Aplikasi computer Base Test dengan PHP Mysqli \& Bootratrap Penerbit Lokomedia.

[2] Tata Sutabri, (2012), Konsep Sistem Informasi, Penerbit Andi

[3] Pressman, Roger S.. 2007. "Rekayasa Perangkat Lunak : Pendekatan Praktisi (Buku II) Roger S Pressman: Di Terjemahkan oleh LN Hamaningrum. Andi,Yogyakarta

[4] Rohi Abdulloh (2017), Amazing Project Aplikasi Ujian Online Full Ajax Penerbit CV. ASFA Solution

[5] https://rarakotabumi.wordpress.com/tag/a plikasi-menu-restoranandroid/LAMPIRAN di akses tgl 19 Juli 2017

[6] http://www.softwarerestoran.info/ di akses tgl 19 Juli 2017

\section{REFERENSI}

